\title{
Retraction Note to: Different Aspects of Sartan + Calcium Antagonist Association Compared to the Single Therapy on Inflammation and Metabolic Parameters in Hypertensive Patients
}

\author{
Giuseppe Derosa, ${ }^{1,2,6}$ Arrigo F. G. Cicero, ${ }^{3}$ Anna Carbone, ${ }^{4}$ Fabrizio Querci, ${ }^{5}$ Elena Fogari, ${ }^{1}$ \\ Angela D'Angelo, ${ }^{1}$ and Pamela Maffioli ${ }^{1}$
}

\section{Retraction to: Inflammation (2014) 37(1):154-162 \\ DOI: 10.1007/s10753-013-9724-x}

This article has been retracted at the request of the Editor-in-Chief.

The authors have published results from exactly the same clinical study and patient population in 6 separate articles, without referencing the publications in any of the later articles:

1. Derosa, G., Cicero, A.F.G., Carbone, A., Querci, F., Fogari, E., D'angelo, A., Maffioli, P. 2013. Olmesartan/amlodipine combination versus olmesartan or amlodipine monotherapies on blood pressure and insulin resistance in a sample of hypertensive patients. Clinical and Experimental Hypertension 35: 301-307. doi:10.3109/10641963.2012.721841.

2. Derosa, G., Cicero, A.F.G., Carbone, A., Querci, F., Fogari, E., D'Angelo, A., Maffioli, P. 2013. Effects of an olmesartan/

The online version of the original article can be found at doi: http://dx.doi.org/ 10.1007/s10753-013-9724-x.

\footnotetext{
${ }^{1}$ Department of Internal Medicine and Therapeutics, University of Pavia, Fondazione IRCCS Policlinico S. Matteo, P.le C. Golgi 2, 27100 Pavia, Italy

${ }^{2}$ Center for the Study of Endocrine-Metabolic Pathophysiology and Clinical Research, University of Pavia, Pavia, Italy

${ }^{3}$ Aging and Kidney Diseases, "G. Descovich" Atherosclerosis Study Center, University of Bologna, Bologna, Italy

${ }^{4}$ Hospital Center of Diabetes, Sant'Angelo Lodigiano, Lodi, Italy

${ }^{5}$ Ospedale Pesenti Fenaroli, Alzano Lombardo, Bergamo, Italy

${ }^{6}$ To whom correspondence should be addressed at Department of Internal Medicine and Therapeutics, University of Pavia, Fondazione IRCCS Policlinico S. Matteo, P.le C. Golgi 2, 27100 Pavia, Italy. E-mail: giuseppe.derosa@unipv.it
}

amlodipine fixed dose on blood pressure control, some adipocytokines and interleukins levels compared with olmesartan or amlodipine monotherapies. Journal of Clinical Pharmacy and Therapeutics 38: 48-55. doi:10.1111/ jept.12021.

3. Derosa, G., Cicero, A.F.G., Carbone, A., Querci, F., Fogari, E., D'Angelo, A., Maffioli, P. 2013. Variation of some inflammatory markers in hypertensive patients after 1 year of olmesartan/amlodipine single-pill combination compared with olmesartan or amlodipine monotherapies. Journal of the American Society of Hypertension 7: 32-39. doi:10.1016/ j.jash.2012.11.006.

4. Derosa, G., Cicero, A.F.G., Carbone, A., Querci, F., Fogari, E., D'Angelo, A., Maffioli, P. 2013. Evaluation of safety and efficacy of a fixed olmesartan/amlodipine combination therapy compared to single monotherapies. Expert Opinion on Drug Safety 12: 621-629. doi:10.1517/14740338.2013.816674.

5. Derosa, G., Cicero, A.F.G., Carbone, A., Querci, F., Fogari, E., D'Angelo, A., Maffioli, P. 2014. Different aspects of sartan + calcium antagonist association compared to the single therapy on inflammation and metabolic parameters in hypertensive patients. Inflammation 37: 154-162. doi:10.1007/s10753-0139724-x.

6. Derosa, G., Cicero, A.F.G., Carbone, A., Querci, F., Fogari, E., D'Angelo, A., Maffioli, P. 2014. Results from a 12 months, randomized, clinical trial comparing an olmesartan/amlodipine single pill combination to olmesartan and amlodipine monotherapies on blood pressure and inflammation. European Journal of Pharmaceutical Sciences 51: 26-33. doi:10.1016/ j.ejps.2013.08.031.

In addition, the article in Inflammation contains results published especially in articles 2 and 6 , which is the main reason for retraction of the article in Inflammation.

The publisher apologizes for the inconvenience caused. 